\title{
Shape-Controlled CuCl Crystallite Catalysts for Aniline Coupling
}

\author{
Ting Xie, Ming Gong, Zhiqiang Niu, Shuai Li, Xiaoyu Yan, and Yadong Li ( $\varangle)$ \\ Department of Chemistry, Tsinghua University, Beijing 100084, China \\ Received: 12 October 2009 / Revised: 21 December 2009 / Accepted: 28 December 2009 \\ (C) The Author(s) 2010. This article is published with open access at Springerlink.com
}

\begin{abstract}
The catalytic activity of crystallites depends mainly upon the arrangement of surface atoms, the number of dangling bonds, and defect site distribution on different crystal planes. Here, we report the shape-controlled synthesis of $\mathrm{CuCl}$ crystallites, including tetrahedra, face-centered-etched tetrahedra, tripod dendrites, and tetrapods. These different morphologies of $\mathrm{CuCl}$ crystallites expose different proportions of $\{111\}$ and $\{110\}$ crystal planes, and materials with a preponderance of $\{111\}$ crystal planes have better catalytic activity in aniline coupling than those with more $\{110\}$ planes.
\end{abstract}

\section{KEYWORDS}

$\mathrm{CuCl}$, aniline coupling, catalytic activity, crystal plane effects

\section{Introduction}

Recently, interest in the reactivity and selectivity of nanocrystals and crystallite catalysts has focused on their shape and crystal plane effects [1-9]. It has been demonstrated that the different reactivities and selectivities of catalysts depend mainly on which specific crystal planes are exposed, because of the diverse arrangements of surface atoms and numbers of dangling bonds on different crystal planes [10-12]. Traditional catalysts are usually composed of polycrystals exposing a variety of crystal planes exhibiting different reactivities; thus, they usually have lower catalytic activity than shape-controlled crystallites. Therefore, the selective synthesis of differently shaped single crystallites with varying proportions of specific crystal planes is an important prerequisite for the investigation of the differences in catalytic activity of these planes, as well as for improving the catalytic properties of materials.

Copper (I) chloride $(\mathrm{CuCl})$ is an important catalyst in many free radical reactions [13-15], especially coupling and polymerization. Its undemanding reaction conditions meet the current interest in developing more efficient and environmentally friendly methods for chemical synthesis, and thus it has attracted great attention. However, there have been few attempts to investigate the catalytic properties of $\mathrm{CuCl}$ crystallites with different shapes and little is known about the effects of different crystal planes in the catalysis of organic reactions by this material. Herein, an one-pot solvothermal route was employed to synthesize $\mathrm{CuCl}$ crystallites [16], and the Diffusion-Controlled Kinetic (DCK) and Surface Chemical Thermodynamics (SCT) models were used to tune the shapes and crystal structures of the crystallites [17-19]. $\mathrm{CuCl}$ crystallites with step-morphologies were successfully synthesized, including tetrahedra, face-centered-etched tetrahedra,

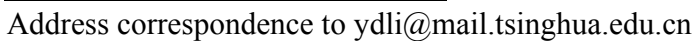


tripod dendrites, and tetrapods. The aerobic oxidative reaction of $p$-toluidine was selected as a model reaction to test the catalytic properties of $\mathrm{CuCl}$ (the reaction is shown in Table 1 [20]). The catalytic activities of $\mathrm{CuCl}$ crystallite catalysts with different proportions of $\{111\}$ and $\{110\}$ crystal planes were compared.

\section{Experimental}

\subsection{Materials}

All the reagents employed in this work, including cupric chloride $\left(\mathrm{CuCl}_{2} \cdot 2 \mathrm{H}_{2} \mathrm{O}\right)$, acetylacetone, ethylene glycol (EG), acetonitrile, $p$-toluidine, potassium carbonate, sodium sulphate, ethanol, and cyclohexane, were analytical grade from the Beijing Chemical Factory. They were used without further purification.

\subsection{Synthesis}

In a typical synthetic procedure, $0.85 \mathrm{~g}$ of cupric chloride $\left(\mathrm{CuCl}_{2} \cdot 2 \mathrm{H}_{2} \mathrm{O}\right)$ was dissolved in $20 \mathrm{~mL}$ of acetylacetone and then thoroughly stirred at room temperature (R. T.) with $20 \mathrm{~mL}$ of ethylene glycol until a homogeneous mixture was obtained. After vigorous stirring for another $10 \mathrm{~min}$, the solution was transferred into a Teflon-lined autoclave of $50 \mathrm{~mL}$ capacity, which was then sealed and heated at $100-140{ }^{\circ} \mathrm{C}$ for $8-72 \mathrm{~h}$. The system was then allowed to cool down to room temperature and products were collected by centrifugation, washed several times with ethanol, and purified.

\subsection{Catalytic experiments}

In the $\mathrm{CuCl}$-catalyzed aerobic coupling of $p$-toluidine, a mixture of as prepared $\mathrm{CuCl}(10 \mathrm{mg}, 0.10 \mathrm{mmol})$, acetonitrile $(5.0 \mathrm{~mL})$, and $p$-toluidine $(1.0 \mathrm{mmol})$ was stirred in air at room temperature for $10 \mathrm{~h}$. The reaction mixture was quenched with an aqueous solution of $\mathrm{K}_{2} \mathrm{CO}_{3}$, followed by extraction of the organic phase using $3 \times 5 \mathrm{~mL}$ portions of diethyl ether. The combined organic extracts were then dried over $\mathrm{Na}_{2} \mathrm{SO}_{4}$, filtered, and concentrated. The residue was purified by column chromatography on silica gel with petroleum ether/ethylacetate (10/1) as eluant. The resulting solution was evaporated to dryness and the resulting solid was weighed; this mass was taken as the yield of 1,2-di-p-tolyldiazene (4,4'-dimethylazobenzene).

\subsection{Characterization}

The as prepared $\mathrm{CuCl}$ crystallites were characterized using a JEOL JSM-6301F scanning electron microscope (SEM) operating at $20 \mathrm{kV}$. Powder X-ray diffraction (XRD) patterns were obtained using a Bruker D8 Advance X-ray diffractometer.

\section{Results and discussion}

Figure 1 shows representative SEM images of differently shaped $\mathrm{CuCl}$ crystallites and their gradual change during the ripening procedure from tetrahedra, to face-centered-etched tetrahedra, to tripod dendrites, and finally to tetrapods. Figure 2

Table 1 Characterization of different morphologies of $\mathrm{CuCl}$ crystallites and their catalytic properties in aniline coupling

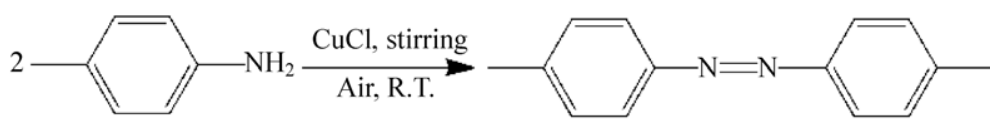

\begin{tabular}{lcccc}
\hline \multicolumn{1}{c}{ Morphology } & $\begin{array}{c}\text { Proportion of }\{111\} \\
(\%)\end{array}$ & $\begin{array}{c}\text { Proportion of }\{110\} \\
(\%)\end{array}$ & $\begin{array}{c}\text { BET surface area } \\
\left(\mathrm{m}^{2} / \mathrm{g}\right)\end{array}$ & $\begin{array}{c}\text { Yield } \\
(\%)\end{array}$ \\
\hline Tetrahedron & 95 & 4 & 0.693 & 55 \\
Face-centered-etched tetrahedron & 76 & 18 & 0.782 & 34 \\
Tripod dendrite & 51 & 37 & 0.819 & 28 \\
Tetrapod & 30 & 67 & 0.721 & 19 \\
\hline
\end{tabular}


shows larger scale SEM images of the different $\mathrm{CuCl}$ samples. It can be seen from these figures that the $\mathrm{CuCl}$ crystallites suffered an etching process. That is, the legs of the $\mathrm{CuCl}$ tetrahedron grew, while the faces became etched during the ripening procedure (Fig. 1 and Fig. S-1 in the Electronic Supplementary Material (ESM)). The DCK and SCT models predict that the increase of reaction temperature (from 100 to $140{ }^{\circ} \mathrm{C}$ ) and elongation of ripening time (from 8 to $72 \mathrm{~h}$ ) will lead to such a process. Obviously, differently shaped $\mathrm{CuCl}$ crystallites expose different crystal planes (Figs. 1 and 2). But due to the one-pot route employed, one sample might contain several different morphologies of $\mathrm{CuCl}$ crystallites, especially gradient face-centeredetched tetrahedra and tripod dendrites (see Fig. S-2 in the ESM). Therefore, the proportions of crystal planes exposed cannot be determined from SEM images but instead, can be approximately obtained from the powder XRD patterns of the materials (Fig. 3). All the diffraction peaks of the $\mathrm{CuCl}$ crystallites can be indexed as a face-centered cubic (fcc) phase

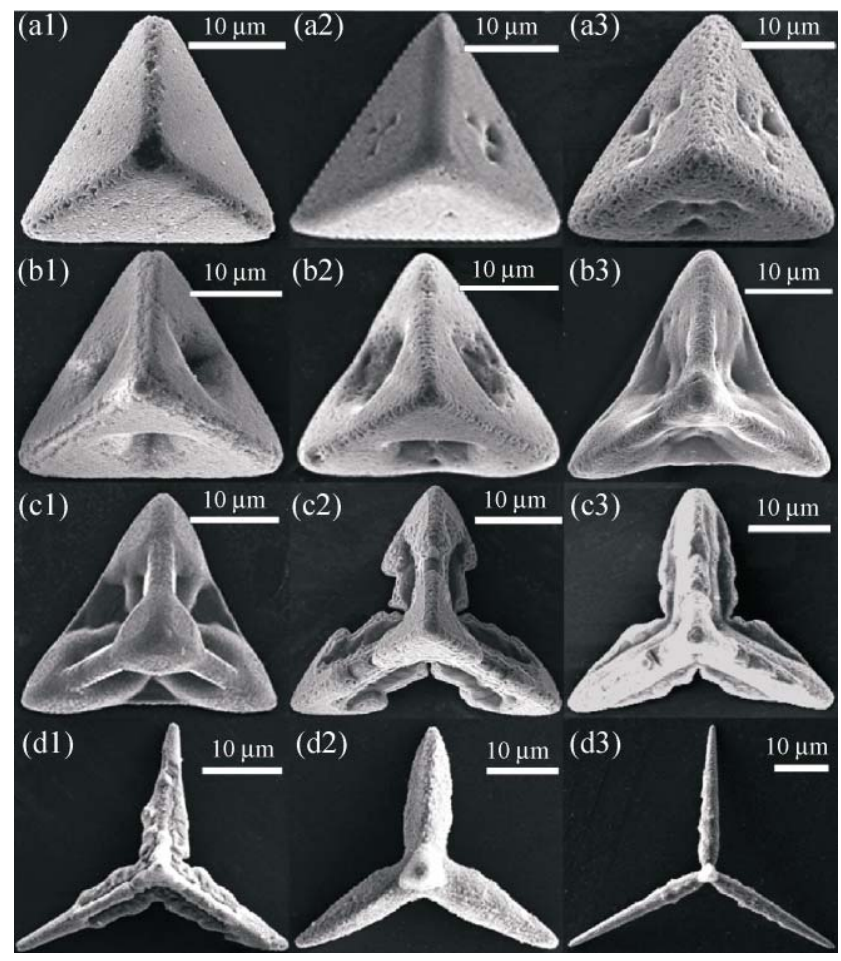

Figure 1 Representative SEM images of differently shaped $\mathrm{CuCl}$ crystallites: (a1, a2, a3) tetrahedron, (b1, b2, b3) face-centeredetched tetrahedron, $(\mathrm{c} 1, \mathrm{c} 2, \mathrm{c} 3)$ tripod dendrite, $(\mathrm{d} 1, \mathrm{~d} 2, \mathrm{~d} 3)$ tetrapod

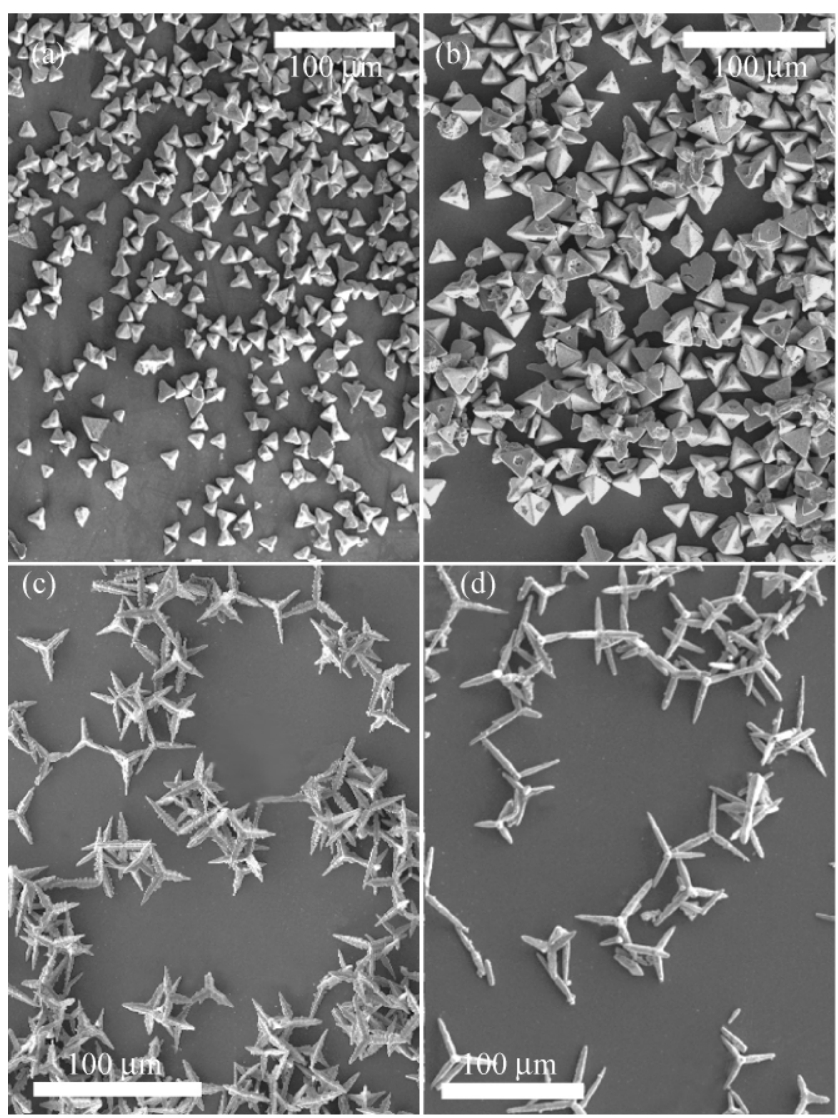

Figure 2 Large-scale SEM images of differently shaped $\mathrm{CuCl}$ crystallites: (a) tetrahedra, (b) face-centered-etched tetrahedra, and (c, d) tripod dendrites

consistent with the values in the literature (JCPDS card No.82-2114). In particular, the relative intensities in the powder XRD patterns approximately represent the ratio of $\{111\}$ to $\{110\}$ crystal planes (Fig. 3). These ratios vary significantly for the tetrahedra, facecentered-etched tetrahedra, tripod dendrites, and tetrapods (Table 1). Note that because of systematic absences, the $\{220\}$ peak in the XRD patterns represents the number of $\{110\}$ planes.

During the oxidative reaction of $p$-toluidine, the $\mathrm{CuCl}$ crystallite catalysts and the reactants form a quasi-homogeneous phase (see Fig. S-3 in the ESM). The yields of 1,2-di- $p$-tolyldiazene $\left(4,4^{\prime}-\right.$ dimethylazobenzene) using $\mathrm{CuCl}$ tetrahedra, facecentered-etched tetrahedra, tripod dendrites, and tetrapods as catalysts were $55 \%, 34 \%, 28 \%$, and $19 \%$, respectively $\left({ }^{1} \mathrm{H}\right.$ NMR data are shown in Fig. S-4 in the ESM). The BET surface areas of $\mathrm{CuCl}$ tetrahedra, 


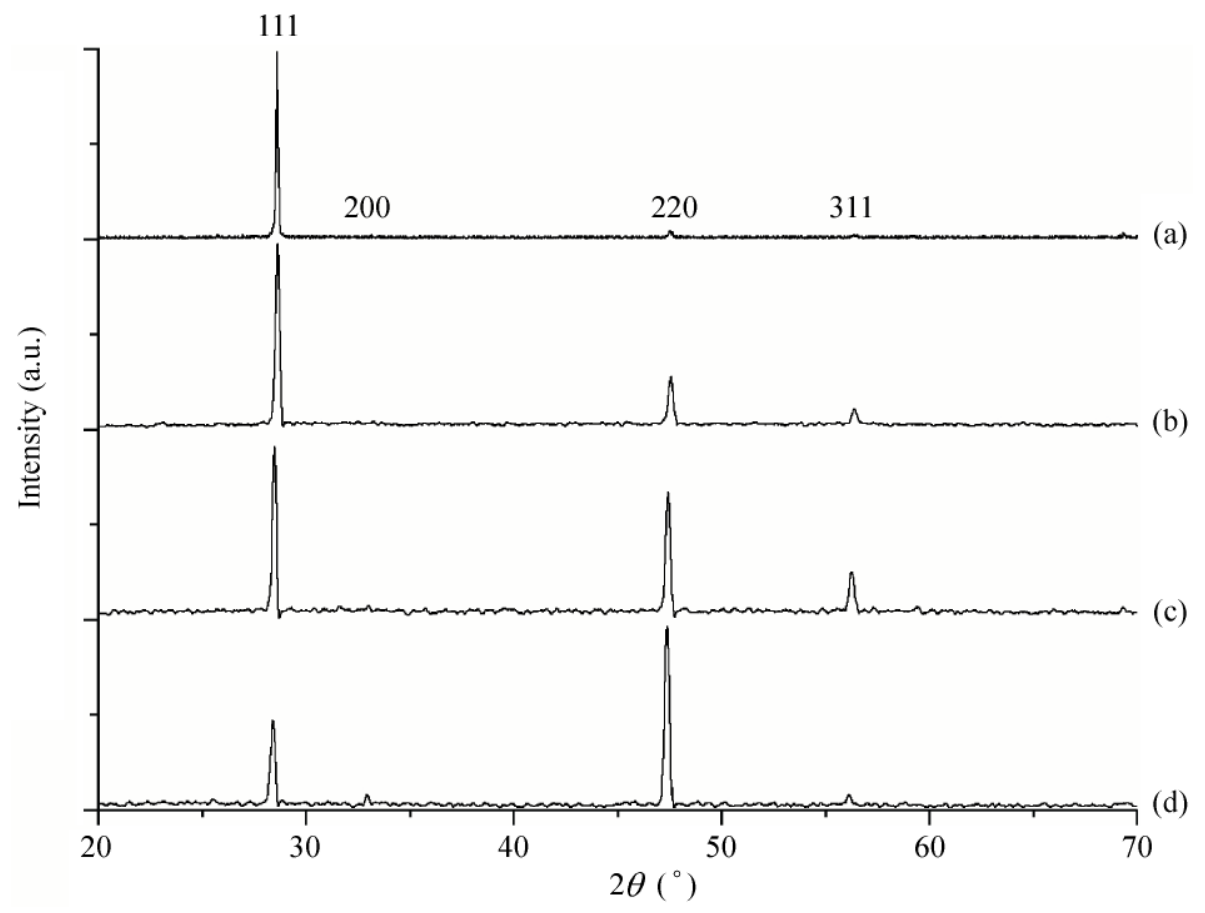

Figure 3 Powder XRD patterns of $\mathrm{CuCl}$ crystallites with different morphologies: (a) tetrahedra, (b) face-centered-etched tetrahedra, (c) tripod dendrites, and (d) tetrapods

face-centered-etched tetrahedra, tripod dendrites, and tetrapods are given in Table 1 . These data show that the size of the $\mathrm{CuCl}$ crystallites is not the key factor in determining catalytic activity, since the $\mathrm{CuCl}$ tetrahedra have the lowest BET surface area but the highest reactivity and the $\mathrm{CuCl}$ tripod dendrites have the largest BET surface area, but relatively poor catalytic activity. Instead, it can be seen from Table 1 that the increasing catalytic activity is correlated with the increasing ratio of $\{111\}$ to $\{110\}$ crystal planes. This result confirms that the crystal plane is the most significant factor affecting the catalytic properties of $\mathrm{CuCl}$ in this reaction and that $\{111\}$ crystal planes have higher catalytic activity than $\{110\}$ planes. This difference between crystal planes may arise from the difference in their structures: for one thing, the surface atom arrangements of $\{111\}$ and $\{110\}$ planes are quite different, and the atomic structure of the former might be more suitable for this oxidative coupling and thus be a more reactive surface; furthermore, the numbers of nearest neighbors in the $\{111\}$ and $\{110\}$ planes are different, which may also contribute to the difference in their catalytic activities (Scheme 1). The
$\{111\}$
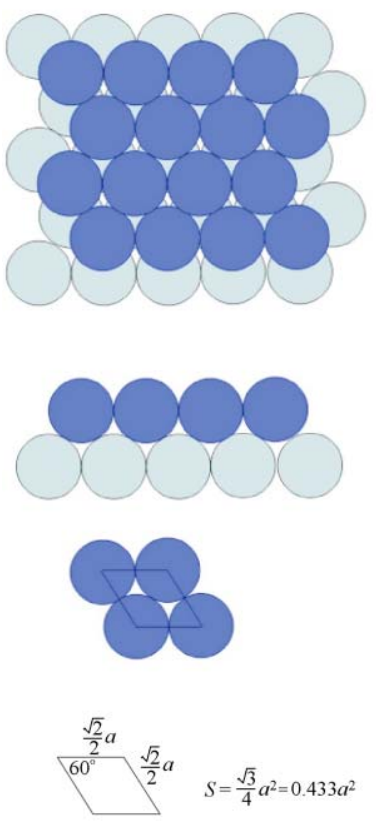

$\{110\}$
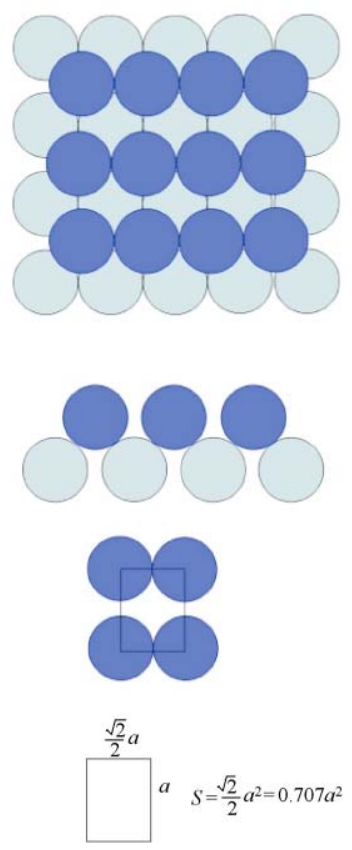

Scheme 1 Representation of surface atom arrangements on $\{111\}$ and $\{110\}$ crystal planes of $\mathrm{CuCl}$ crystallites. The blue and green spheres are the surface layer and the next layer of the $\mathrm{CuCl}$ unit cell, respectively 
powder XRD patterns of the $\mathrm{CuCl}$ crystallites after catalyzing the aniline coupling reaction were similar to those of the materials before reaction. SEM micrographs of the $\mathrm{CuCl}$ crystallites after carrying out the aniline coupling reaction showed (see Fig. S-5 in the ESM) that only a small proportion of crystallites decompose, with the vast majority remaining unchanged. It should be pointed out, however, that the SEM images of the used catalyst show that there are significant amounts of impurities present along with the $\mathrm{CuCl}$ crystallites. These impurities are likely to be over-oxidized organic compounds. Therefore, the $\mathrm{CuCl}$ crystallite catalysts have poor activity when reused in a second aniline coupling reaction. We also confirm that the residual capping groups are not the principal cause of differences in catalytic performance of the materials via IR data. (See Fig. S-6 in the ESM)

\section{Conclusions}

$\mathrm{CuCl}$ crystallites with step-shapes, namely tetrahedra, face-centered-etched tetrahedra, tripod dendrites, and tetrapods, have been successfully synthesized via a solvothermal process. These differently shaped $\mathrm{CuCl}$ crystallites have very different ratios of exposed $\{111\}$ and $\{110\}$ crystal planes. The catalytic activity of the $\{111\}$ crystal planes in aniline coupling is better than that of the $\{110\}$ planes. Since the nature of the exposed crystal planes plays an important role in determining the catalytic properties of the $\mathrm{CuCl}$ crystallites we have good reasons to believe that shape-controlled synthesis of other catalysts is expected to bring new opportunities for the design, tuning, and control of chemical activity, specificity, and selectivity of these materials.

\section{Acknowledgements}

This work was supported by National Natural Science Foundation of China (NSFC) (No. 90606006), the State Key Project of Fundamental Research for Nanoscience and Nanotechnology (No. 2006CB932300), and the Key Grant Project of the Chinese Ministry of Education (No. 306020)
Electronic Supplementary Material: Additional SEM images, NMR spectrum, and IR spectrum are available in the online version of this article at http://dx.doi.org/10.1007/s12274-010-1020-6 and are accessible free of charge.

Open Access: This article is distributed under the terms of the Creative Commons Attribution Noncommercial License which permits any noncommercial use, distribution, and reproduction in any medium, provided the original author(s) and source are credited.

\section{References}

[1] Burda, C.; Chen, X.; Narayanan, R.; El-Sayed M. A. Chemistry and properties of nanocrystals of different shapes. Chem. Rev. 2005, 105, 1025-1102.

[2] Zhou, K. B.; Wang, X.; Sun, X. M.; Peng Q.; Li, Y. D. Enhanced catalytic activity of ceria nanorods from welldefined reactive crystal planes. J. Catal. 2005, 229, 206-212.

[3] Zhou, K. B.; Xu, R.; Sun, X. M.; Chen, H. D.; Tian, Q.; Shen, D. X.; Li, Y. D. Favorable synergetic effects between $\mathrm{CuO}$ and the reactive planes of ceria nanorods. Catal. Lett. 2005, 101, 169-173.

[4] Zhou, K. B.; Wang, R. P.; Xu, B. Q.; Li, Y. D. Synthesis, characterization and catalytic properties of $\mathrm{CuO}$ nanocrystals with various shapes. Nanotechnology 2006, 17, 3939-3943.

[5] Zhang, Y. W.; Grass, M. E.; Habas, S. E.; Tao, F.; Zhang, T. F.; Yang, P. D.; Somorjai, G. A. One-step polyol synthesis and Langmuir-Blodgett monolayer formation of size-tunable monodisperse rhodium nanocrystals with catalytically active (111) surface structures. J. Am. Chem. Soc. 2007, 111, 12243-12253.

[6] Bratlie, K. M.; Lee, H.; Komvopoulos, K.; Yang, P. D.; Somorjai, G. A. Platinum nanoparticle shape effects on benzene hydrogenation selectivity. Nano Lett. 2007, 7, 3097-3101.

[7] Tian, N.; Zhou, Z. Y.; Sun, S. G.; Ding, Y.; Wang, Z. L. Synthesis of tetrahexahedral platinum nanocrystals with highindex facets and high electro-oxidation activity. Science 2007, 316, 732-735.

[8] Si, R.; Flytzani-Stephanopoulos, M. Shape and crystal-plane effects of nanoscale ceria on the activity of $\mathrm{Au}-\mathrm{CeO}_{2}$ catalysts for the water-gas shift reaction. Angew. Chem. Int. Ed. 2008, 47, 2884-2887.

[9] Hu, L. H.; Peng, Q.; Li, Y. D. Selective synthesis of $\mathrm{Co}_{3} \mathrm{O}_{4}$ nanocrystal with different shape and crystal plane effect on 
catalytic property for methane combustion. J. Am. Chem. Soc. 2008, 130, 16136-16137.

[10] Liu, X. W.; Zhou, K. B.; Wang, L.; Wang, B. Y.; Li, Y. D. Oxygen vacancy clusters promoting reducibility and activity of ceria nanorods. J. Am. Chem. Soc. 2009, 131, 3140-3141.

[11] Wang, D. S.; Xie, T.; Li, Y. D. Nanocrystals: Solutionbased synthesis and applications as nanocatalysts. Nano Res. 2009, 2, 30-46.

[12] Xie, X. W.; Li, Y.; Liu, Z. Q.; Haruta, M.; Shen, W. J. Low-temperature oxidation of $\mathrm{CO}$ catalysed by $\mathrm{Co}_{3} \mathrm{O}_{4}$ nanorods. Nature 2009, 458, 746-749.

[13] Rousselet, G.; Capdevienlle, P.; Maumy, M. Copper(I)induced addition of amines to unactivated nitriles: The first general one-step synthesis of alkyl amidines. Tetrahedron Lett. 1993, 34, 6395-6398.

[14] Cao, Y.; Hu, J. C.; Yang, P.; Dai, W. L.; Fan, K. N. CuCl catalyst heterogenized on diamide immobilized SBA-15 for efficient oxidative carbonylation of methanol to dimethylcarbonate. Chem. Commun. 2003, 908-909.
[15] He, C.; Chen, C.; Chen, J.; Liu, C.; Liu, W.; Liu, Q.; Lei, A. W. Aryl halide tolerated electrophilic amination of arylboronic acids with $\mathrm{N}$-chloroamides catalyzed by $\mathrm{CuCl}$ at room temperature. Angew. Chem. Int. Ed. 2008, 47, 6414-6417.

[16] Li, Q.; Shao, M. W.; Yu, G. H.; Wu, J.; Li, F. Q.; Qian, Y. T. A solvent-reduction approach to tetrapod-like copper(I) chloride crystallites. J. Mater. Chem. 2003, 13, 424-427.

[17] Xie, T.; Li, S. A.; Peng, Q.; Li, Y. D. Monodisperse $\mathrm{BaF}_{2}$ nanocrystals: Phases, size transitions, and self-assembly. Angew. Chem. Int. Ed. 2009, 48, 196-200.

[18] Xie, T.; Li, S. A.; Wang, W. B.; Peng, Q.; Li, Y. D. Nucleation and growth of $\mathrm{BaF}_{(\mathrm{x})} \mathrm{Cl}_{(2-\mathrm{x})}$ nanorods. Chem. Eur. J. 2008, 14, 9730-9735.

[19] Li, S. A.; Xie, T.; Peng, Q.; Li, Y. D. Nucleation and growth of $\mathrm{CeF}_{3}$ and $\mathrm{NaCeF}_{4}$ nanocrystals. Chem. Eur. J. 2009, 15, 2512-2517.

[20] Lu, W. C.; Xi, C. J. CuCl-catalyzed aerobic oxidative reaction of primary aromatic amines. Tetrahedron Lett. 2008, 49, 4011-4015. 